\title{
Geographical Information System for Mapping and Analysis of Agricultural Areas in Merauke Regency
}

\author{
Marsujitullah Marsujitullah ${ }^{*}{ }^{*}$ Fransiskus X. Manggau ${ }^{1}$, Try Adrianto Darsono ${ }^{1}$, Agustan Latif $^{2}$ \\ ${ }^{1}$ Department of Informatics, Faculty of Engineering, Universitas Musamus, Merauke 99600, Indonesia \\ ${ }^{2}$ Department of Information System, Faculty of Engineering, Universitas Musamus, Merauke 99600, Indonesia
}

\begin{abstract}
This Geographical Information System Mapping and Analysis Study aims to map and analyze the range of potential seed plant returns in several sub-districts in Merauke, which consists of several criteria for structural land use and land use intensity. Building Management, Circulation and Connecting Systems, Open Space and Green Systems, Quality Environmental Management, Environmental Infrastructure and Utilities Systems and Building and Environmental Conservation. This research was made using Simple Additive Weighting (SAW) which allows the search for optimal alternative solutions and the latest technological developments related to a method and presentation of information. The final result of this research is that web-based GIS is expected to be a source of reference / reference that is easily accessed by stakeholders related to agriculture, providing an overview of the various potentials of farming, especially sub-districts that have potential. availability of suitable land, provides an overview of the quantity of agricultural land use that has been utilized, and can be used as a guideline for policy development in the field of superior agriculture at the regional and national levels.
\end{abstract}

Keywords: Geographic Information System, SAW, Agriculture

\section{Introduction}

Indonesia has a large food area, especially for agricultural variants, such as rice, tubers and various types of beans. however, there is no system or tool used among farmers to monitor the entirety of each agricultural and plantation land, so they still use the old way of monitoring manually.

The majority of Indonesians work as farmers, for this reason the role of the agricultural sector is one of the supporters in economic development that is able to provide a solution for the wider Indonesian community, especially in Merauke Regency [1]. Merauke Regency is an agricultural district located in Papua Province, which is also directly adjacent to Papua New Guine State, and is one of the national food storage areas engaged in the agricultural sector [2]. As an agricultural agrarian area, it is appropriate for the Mapping and Analysis of Agricultural Areas in Merauke Regency to be very good, given the goal to be achieved, namely to map and re-analyze the variety of superior agricultural product potentials in several districts in Merauke Regency, which consists of several criteria, namely Allocation Structure Land, Land Use Intensity, Building Layout, Circulation and Connecting Systems, Open Space and Green Systems, Environmental Quality Management, Environmental Infrastructure and Utilities Systems and Building and Environmental Preservation.
This research was created using the Simple Additive Weighting (SAW) method which allows to find optimal alternative solutions and the development of the latest technology related to the method and presentation of information.

The final result of this research is in the form of a Geographical Information System which is expected to be a reference source that is easily accessed by stakeholders related to agriculture, provides an overview of the variety of superior agricultural potentials that are owned, especially sub-districts that have suitable land potential, and provide an overview of the quantity of utilization. agricultural land that has been used, and can be used as a guideline in formulating policies for the development of superior areas in the agricultural sector at the regional and national levels.

\section{Supporting Theory}

\subsection{Agricultural Development}

Agricultural development theories are discussed on the economic aspects of agricultural development and agricultural issues, in general there are four points of view (A.T. Mosher): 1. The sectoral view is that agriculture is viewed as an economic sector against other sectors in the national economy. 2. View of

\footnotetext{
* Corresponding author : marsujitullah@unmus.ac.id
} 
efficiency problems in the use of agricultural production factors. 3. From a commodity perspective, especially the main commodity produced. 4 . View from the point of view of regional development. The first and fourth views can be classified as a macroeconomic approach, while the second and third views are as a microeconomic approach. Merauke Regency, which is an area with very good agricultural potential, is very good at analyzing and mapping the superior potential of the agricultural sector, because by knowing the superior potential in the agricultural sector, it can be predicted that the distribution of agricultural land and yields in each potential district and as a recommendation for utilization. suitable agricultural land $[2,3]$.

On the other hand, from a macroeconomic perspective, agricultural development can be analyzed through three frameworks of thought: 1. The role of agriculture in agricultural development 2. Economic characteristics of traditional agriculture 3. The economic process of agricultural modernization, the first and second frameworks are the same as sectoral view. The government always considers that farmers are conservative and it is difficult to accept suggestions in adopting technology.

The approach to agricultural development in terms of commodities is mainly based on the fact that the major "role" of these commodities is national or for a certain area, for example rubber, copra coffee and so on. The weakness of this approach becomes clear if there is less attention to the relationship and its broader implications. For example, rice analysis, which is always focused on rice self-sufficiency, will waste more economic resources if it is not considered its relationship with world economic development [4].

\subsection{Maps and Mapping}

A map is a graphical presentation of a collection of data and information according to its location in two dimensions. In terms of its role, maps are a form of presenting spatial (spatial) information about the earth's surface to be used in decision making. While mapping is a form of graphical communication between map makers and users that has long been known to people [1, 5].

Maps and mapping are needed in various fields. In the world of agriculture, one of the problems that often occurs is the lack of knowledge about the distribution of agriculture. This is due to the existence of information technology support, especially in the GIS sector, which has not reached the agricultural sector in several remote areas or newly developed areas. For example, in Merauke Regency, information on agricultural distribution is only in the form of recording data, which is then processed into books or articles. If the government is aware of the use of map processing and mapping using information technology, it will be more effective and accurate in the distribution of information on the distribution of agriculture in Merauke Regency. With the mapping, the agricultural distribution can be presented visually into GIS, making it easier for the government to control and make decisions in the distribution of agriculture in the context of selecting superior agricultural areas in each District in Merauke Regency.

\subsection{Geographicial Information System - GIS}

Geographical Information System or often referred to as Geospatial Information System is an information system used to compile, store, revise and analyze data and attributes that refer to the location or position of objects on earth [1] This means that data or information that refers to the location or position of objects on earth is termed spatial data or information, while attributes describe the characteristics of the spatial data. More specifically, the components of spatial data include geographic position / location, attribute data, spatial relationships and time.

\subsection{GIS Data Model}

Data in GIS are grouped into two parts, namely spatial data and non-spatial data. Spatial data is data that contains the location of an object on a map based on the geographic position of the object on the earth using a coordinate system. Spatial data has two basic elements, among others $[6,7]$ :

a) Location

Location generally refers to the geographic location of an object in the Earth's coordinate system, however other geographic codes can also be used. For example, zip code.

b) Attributes

Attributes are the basic characteristics or characteristics of an object, for example the name of the location, gender and others. Non-spatial data is data that represents descriptive aspects of the phenomena being modeled. This data is often called attribute data. In a map, attributes are usually represented as text or map legend.

This journal refers to 8 criteria and 9 alternatives. The criteria taken are based on the Minister of Public Works Regulation No. 06 / PRT / M / 2007 concerning General Guidelines for Building and Environmental Planning, while the alternatives used are taken from Merauke in the number 2021.

Table 1. Criteria for drafting the regional design component concept

\begin{tabular}{|c|c|l|}
\hline No & Criteria & \multicolumn{1}{|c|}{ Description } \\
\hline 1 & C1 & Land Allocation Structure (LAS) \\
\hline 2 & C2 & Land Use Intensity (LUS) \\
\hline 3 & C3 & Building Design (BD) \\
\hline 4 & C4 & $\begin{array}{l}\text { Circulation and Connecting Systems } \\
\text { (CCS) }\end{array}$ \\
\hline 5 & C5 & $\begin{array}{l}\text { Open space and green systems } \\
\text { (RTH) }\end{array}$ \\
\hline 6 & C6 & $\begin{array}{l}\text { Environmental Quality } \\
\text { Management (EQM) }\end{array}$ \\
\hline 7 & C7 & $\begin{array}{l}\text { Infrastructure and Utility Systems } \\
\text { Environment (IUSE) }\end{array}$ \\
\hline 8 & C8 & $\begin{array}{l}\text { Building Preservation and } \\
\text { Environment (BPE) }\end{array}$ \\
\hline
\end{tabular}




\subsection{Supporting Criteria}

Systematically, the concept must include a comprehensive and integrated idea of the components of agricultural analysis design contained in the technical guidelines for agricultural area planning, as well as explain several criteria (Regulation of the Minister of Public Works Number 06 / PRT / M / 2007 concerning General Guidelines for Planning Building and Environmental Planning) and the Regulation of the Minister of Public Works are used to compile criteria on components of the design of government office areas, which consist of 8 criteria.

a) Land Allocation Structure

The structure of the use of the vacant area is part of the planning and design of the area which is an important part as the management / land use that has been determined for a certain planning area based on the rules and design of the area that has been determined, with the benefits obtained namely improving the balance of the quality of environmental life by forming spaces. Urban space / living environment that is physically (vibrant) and economic (viable), livable and balanced, and improves the quality of life of users and the quality of the environment.

b) Land Use Intensity

Used in accordance with the level and area of the land/location in order to achieve efficiency and effectiveness of reasonable use. The components of the LUI arrangement are the basic building coefficient, building floor coefficient, green area coefficient, land area coefficient, building boundary line.

c) Building Design

Spatial planning is a way or meaning of the use of space or land that is used properly and correctly, covering various aspects including images or image appearances for an area from a height that can create and define various qualities of urban space in describing existing activities, especially those that take place in space public.

d) Circulation System and Connecting Line

The circulation and connecting system is part of the road and movement network, and there is related circulation such as public, private, local and informal bicycles, in addition to pedestrians, transit facilities, parking systems, environmental service planning, other liaisons related to the system.

e) Open Space and Green Systems

The Open Space System and Green Planning are components of regional design, an important part after the architectural planning design, considering that it is also an integral part of making and designing a planning system and green open space.

f) Environmental Quality Management

Environmental quality management is part of the form of creating an area or other part of the environment for information and has its own specificity, with the benefits it has, namely to unite the area as a quality and good environment, with special characteristics according to its identity.

g) Environmental Infrastructure and Utility Systems The basic physical completeness of an environment whose procurement allows an environment to operate and function as it should. The benefit is to improve the quality of the planning area which ensures the availability of concrete support for existing physical activities.

h) Preservation of Buildings and the Environment In a broader sense, conservation can include an act of management or management of a unit of living organism in the form of a natural environment, such as a nature reserve area, or a built environment such as an urban area.

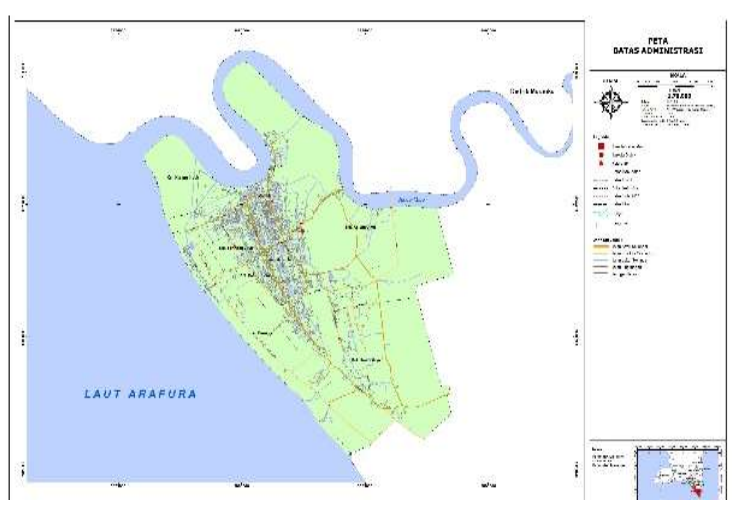

Fig. 1. Administrative Boundary Map

Table 2. Alternative Location Planning

\begin{tabular}{|c|c|l|}
\hline No & Alternative & \multicolumn{1}{|c|}{ Description } \\
\hline 1 & A1 & Semangga District \\
\hline 2 & A2 & Tanah Miring District \\
\hline 3 & A3 & Kurik District \\
\hline 4 & A4 & Malind District \\
\hline 5 & A5 & Naukenjeray District \\
\hline 6 & A6 & Anim Ha District \\
\hline 7 & A7 & Jagebob District \\
\hline 8 & A 8 & Okaba District \\
\hline 9 & A9 & Kimaam District \\
\hline
\end{tabular}




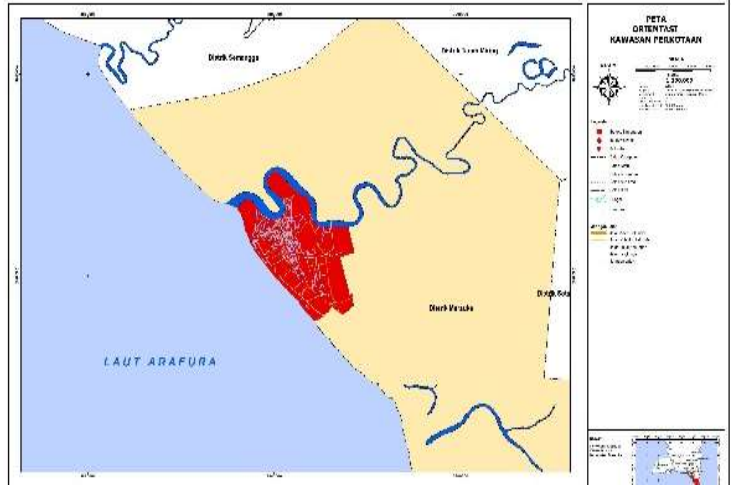

Fig. 2. Urban Boundary Orientation Map

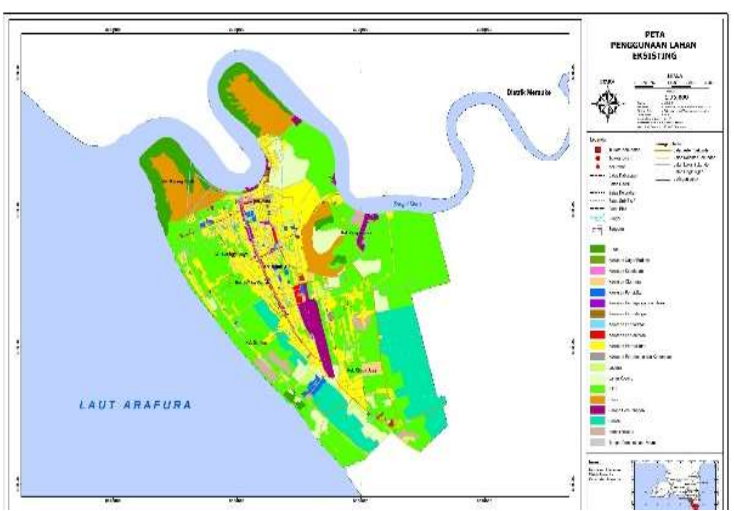

Fig. 3. Existing Land Use Map

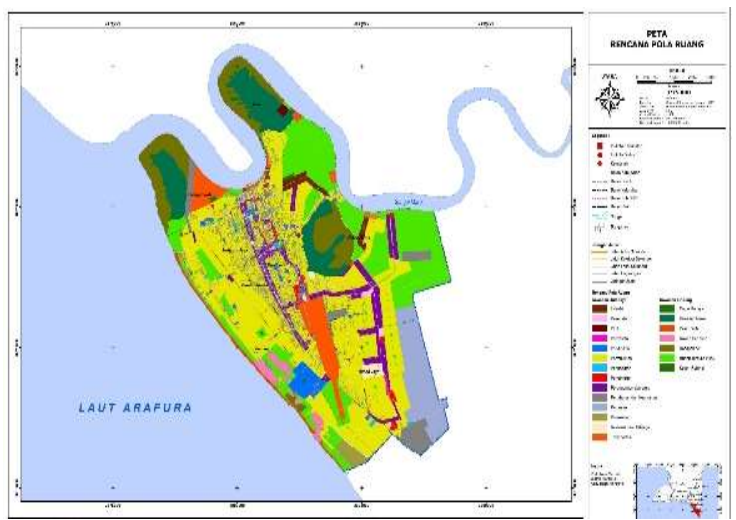

Fig. 4. Spatial Pattern Plan Map

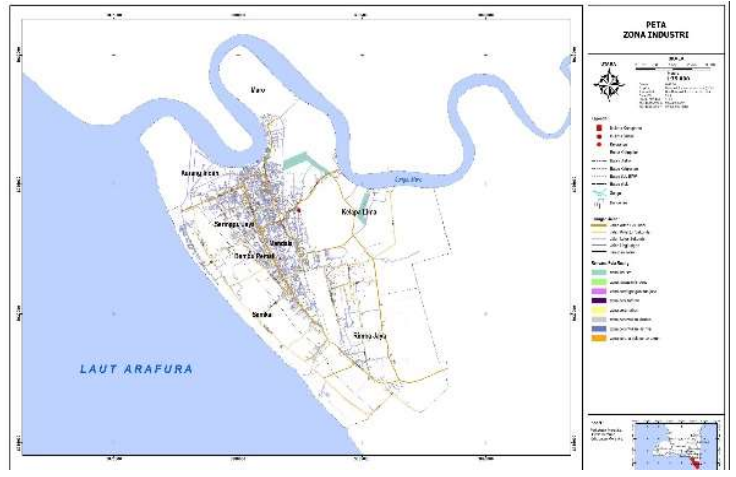

Fig. 5. Industrial Zone Map

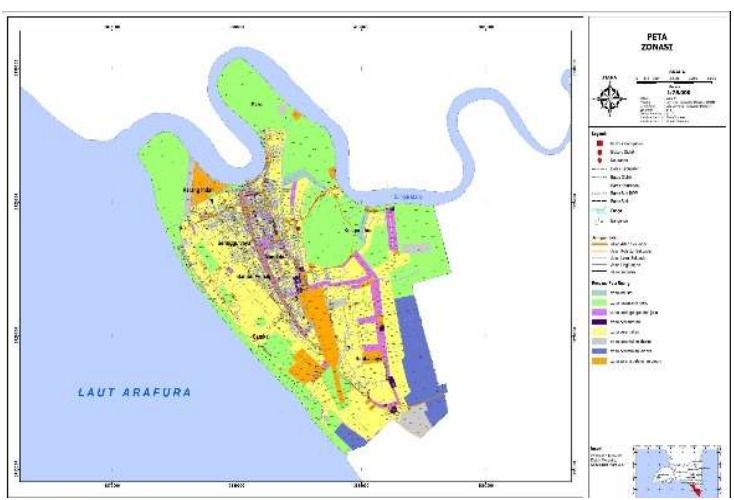

Fig. 6. Zoning Map

\section{Methods}

\subsection{Research Procedure}

There are several stages of research procedures carried out in this study, namely research data collection, data identification and processing, system design, system implementation, and system testing. The description of the research procedure is as shown in Figure 7.
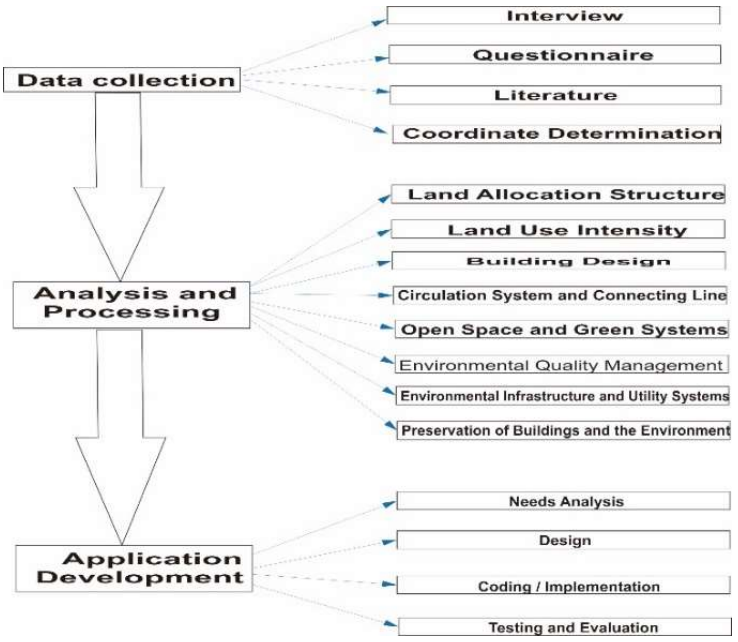

Fig. 7. Research Stages Flowchart

The explanation of each stage is as follows:

a) Needs Analysis

At this stage of the needs analysis, the researcher analyzes the system requirements to be built, such as maps, data to be included in the map, as a reference used to design and implement the system according to the results of the analysis.

b) System planning

At this stage, the researcher conducts a design in accordance with the results of the system requirements analysis, starting from map digitization, input design, process, output design and data relationships.

c) Coding / System Implementation

At this stage, the researcher will implement the results of the analysis and system design. 
d) Trial and Evaluation Is the testing phase of the system that has been made, whether it is feasible or not to be implemented, as well as evaluating the weaknesses and strengths of the system.

\section{Location of Research, Data Analysis, Implementation Results and Validation}

\subsection{Research Facilities}

The research location was carried out in Merauke Regency by taking samples in rice fields in several subdistricts spread across Merauke, as well as other supporting locations according to the available zoning, according to the data and evaluations carried out, using other supporting applications. The data obtained and considered important are input in the system that is built. In addition, data synchronization with local governments is needed to support research that is being carried out, as well as data collection from Merauke in 2021. All available data will be sorted and entered on the server, until it is deemed necessary to make a map.

\subsection{Data Analysis}

In making the existing system, the results of the data analysis will be included in the system, which will also be a system development if needed. In a system that will produce data input data in the form of zoning information, both agricultural areas, land area plans, and urban areas that may be needed as input for decision makers. In addition, as another support, the Google Maps feature is also needed to make it easier to access the mapped locations.

\subsection{SAW Implementation Results}

The initial stage of the SAW processing result process is to determine the criteria that will be used as a reference in making decisions, then determine the suitability rating of each alternative on each criterion. After that, make a decision matrix based on the criteria, then normalize the matrix based on the equation that is adjusted to the type of attribute, so that a normalized matrix is obtained [8]. After getting the normalized matrix results, the results of the cranking will be obtained from the sum of the normalized matrix multiplication with weight vectors using AHP.

\subsection{Validation Process}

In this study, the reference in testing the level of validity is to use the Merauke Regency Spatial Planning rules, which are supported by data on Merauke in numbers 2021. This validation process uses the results of the SAW method calculation analysis, using a weighted value, namely AHP. The results of the SAW calculation will be compared with the Merauke Regency government planning based on the results of the ranking value. The following are the results of the comparative analysis.

Table 3. Comparison of the calculation results of the SAW analysis and Government Plan.

\begin{tabular}{|c|c|c|c|}
\hline No & Alternative Name & $\begin{array}{c}\text { SAW } \\
\text { Results }\end{array}$ & Government \\
\hline 1 & Semangga District & 0.9235 & 0.8968 \\
\hline 2 & $\begin{array}{c}\text { Tanah Miring } \\
\text { District }\end{array}$ & 0.8799 & 0.8434 \\
\hline 3 & Kurik District & 0.8427 & 0.7863 \\
\hline 4 & Malind District & 0.7776 & 0.6162 \\
\hline 5 & Naukenjeray & 0.6891 & 0.5140 \\
\hline 6 & District & 0.6541 & 0.4102 \\
\hline 7 & Jagim Ha District & 0.5591 & 0.2838 \\
\hline 8 & Okabab District & 0.5292 & 0.2777 \\
\hline 9 & Kimaam District & 0.4360 & 0.1460 \\
\hline
\end{tabular}

\section{Conclusion}

An information system has been built for the distribution and analysis of agricultural areas in Merauke Regency. This system is built using the implementation of the use of geographic information systems and the use of the method using the SAW method.

1. The SAW method which is implemented with the concept of analysis of several criteria and alternatives to the Regional Spatial Plan (RSP), as well as support for Merauke in numbers 2021, so that it has validation results. The SAW method has a good level of accuracy during the process of comparing each of the criteria against the agricultural analysis regional decision making.

2. The SAW method uses a weighted value, namely AHP. AHP weighting is considered to be more objective in the assessment. The weighting results are implemented into a GIS map. so that you can see a map of the distribution of agriculture in Merauke Regency

\section{References}

1. Marsujitullah, Z. Zainuddin, S. Manjang, and A. S. Wijaya, "Rice Farming Age Detection Use Drone Based on SVM Histogram Image Classification," J. Phys. Conf. Ser., vol. 1198, no. 9, (2019).

2. Implementation of Location based Services in Android using GPS and Web Services," vol. 9, no. 1, pp. 237-242, (2012).

3. M. F. Al-Sa'd, A. Al-Ali, A. Mohamed, T. Khattab, and A. Erbad, "RF-based drone detection and identification using deep learning approaches: An initiative towards a large open source drone database," Futur. Gener. Comput. Syst., vol. 100, pp. 86-97, (2019). 
4. O. Nasario-Junior, P. R. Benchimol-Barbosa, and J. Nadal, "Beat-to-beat T-peak-T-end Interval Duration Variability Assessed by RR-Interval Histogram Analysis in Healthy Sedentary and Athlete," 2017 Comput. Cardiol. Conf., vol. 44, pp. 2-5, (2018).

5. F. X. Marsujitullah and R. Manggau, "Classification Of Paddy Growth Age Detection Through Aerial Photograph Drone Devices Using Support Vector Machine And Histogram Methods, Case Study Of Merauke Regency Students' Perceptions towards the Grammar Teaching at English Literature Department of," Artic. ID IJMET_10_03_187 Int. J. Mech. Eng. Technol., vol. 10, no. 3, pp. 1850-1859, (2019).

6. Howard, J. A. Penginderaan Jauh Untuk Sumber Daya Hutan, Teori dan Aplikasi, Gajah Mada University Press, Jogjakarta. (1996).

7. Wibowo, A, Djamaluddin, R. dan Hendrarto, G. Remote Sensing and Geographic Information System BPPT Agency For the Assesment and Aplication of Technology, Jakarta. (1994).

8. Marsujitullah, Rachmat, Agus Prayitno and M Y Zamhuri. Decision support system determination of acceptance of employees not civilian state employees (PBPNS) in LPP RRI Merauke using simple additive weighting method, IOP Conf. Ser. Earth Environ. Sci. 343 012177, (2019). 